\title{
Monseñor Christophe Munzihirwa Amigo de los pobres y mártir de la paz
}

\author{
Ghislain Tshikendwa, S. J.* \\ Editor de la revista Congo-Afrique \\ Kinshasa- RD Congo
}

Por haber defendido valientemente a los "pueblos crucificados" y por haber actuado en favor de la paz y la justicia, Monseñor Christophe Munzihirwa fue cobardemente asesinado el 29 de octubre de 1996 en Bukavu, República Democrática del Congo, donde había sido arzobispo desde el 27 de marzo de 1994. Muchos ven hoy en él a "un mártir de la paz y de la justicia". Bruno Chenu, en un editorial del periódico La Croix, del 2 de noviembre de 1996, escribía: "Monseñor Claverie el $1^{\circ}$ de agosto, Monseñor Ruhuna el 9 de septiembre en Burundi y Monseñor Munzihirwa el 29 de octubre en Zaire, por no citar más que obispos, pagaron un precio por su compromiso en favor de la justicia y de la paz. De esta forma han expuesto ante los ojos del mundo el martirio de los pueblos africanos,

* El autor es un jesuita de la República Democrática del Congo, miembro del Centre d'Etudes pour l'Action Sociale y editor la revista Congo-Afrique. El artículo que publicamos es una reelaboración en base a dos textos. El primero es su artículo "Notre responsabilité pour la paix. Réflexions autour de la pensée de Mgr Christophe Munzhihirwas s.j. “, Congo-afrique, 409 (2006) 396-407. El segundo es un texto, no publicado, "Mgr. Christophe Munzihirwa: Ami des pauvres et martyr de la paix!“.

1. Joseph Mukabalera Cigwira, "Monseigneur Christophe Munzihirwa, Romero du Congo? Les concepts de Martyre, de Béatification et Canonisation revisité à la lumière de la martyrologie et de l'expérience pastorale de Mons. Munzihirwa, Archevêque de Bukavu (Sud-Kivu/ RDC)", Tesis de Doctorado en Filosofía y Letras, Universidad de Lovaina, Bélgica, 2003-2004, p. 302. También es de interés la lectura de Benjamín Farhi Bagaya, "Monseñor Munzihirwa: pastor y profeta. Compromiso con una evangelización integral”, Memoria de Licenciatura en Teología, FCK, 2000. 
que, en medio de la violencia más absurda y de la deshumanización más total, no perecen. Firmaron su ministerio de pastores con su propia sangre, mezclándola con la de Cristo, el cordero pascual".

Monseñor Munzihirwa fue abatido con su motorista mientras, como buen pastor, se ocupaba, de la suerte de la población de Bukavu, aterrorizada y desorientada ante el avance fulgurante de las tropas de la Alianza de Fuerzas Democráticas para la Liberación del Congo y la derrota consiguiente de las Fuerzas Armadas del Zaire, que habían permanecido fieles al mariscal Mobutu.

Los testimonios de unos y otros lo confirman. "La renuncia lamentable de la mayor parte de los responsables administrativos y militares hizo de Monseñor prácticamente la única autoridad que se ocupaba realmente de la suerte de la población desorientada". Mzee Munzihirwa - "Mzee" significa "anciano", "prudente", y así firmaba sus artículos en la revista Congo-Africa- con el paso de los años llegó a ser un pastor que cuidó de todos los hombres y de todo el hombre. Al precio, sin duda, de una ascesis intelectual y espiritual, este hombre de Dios, paso a paso, inspiró confianza. Y dejó el recuerdo de hombre valiente, lúcido y apasionado con un alto sentido de paz y justicia, en los corazones de aquellos que se le acercaron.

Mzee Munzihirwa murió mártir, pero durante su vida, en medio de la guerra y la pobreza, trabajó para que la vida llegase a su pueblo. Lo formuló en palabras importantes de aquellos años: paz y desarrollo. Y a la paz y al desarrollo aspiraban las poblaciones congoleñas, heridas por rebeliones recurrentes y por la pobreza indescriptible que aquéllas dejaban como secuela. Ya en 1967 el papa Pablo VI había escrito su encíclica Populorum Progressio - "El desarrollo de los pueblos" - donde afirmaba que el desarrollo es el nuevo nombre de la paz (n. 76). Debe ser integral, tiene que tener en cuenta a todo el hombre y a todos los hombres $^{3}$. Mzee Munzihirwa lo comprendió muy bien y trabajó por ello. Hizo conscientes a unos y otros de la necesidad de construir la paz, como fundamento de cualquier desarrollo integral. Los numerosos testimonios sobre su vida, y sus propios escritos, muestran que sin la paz no se puede entender el progreso humano. Y se esforzaba por recordarlo. "La guerra siempre es odiosa. Quienes aman a esta tierra, son quienes trabajan para construir estructuras de justicia, de perdón y de paz"4.

2. In memoriam: Christophe Munzihirwa, S.J. Archevêque de Bukavu. Serviteur et témoin, Kinshasa, Editions Loyola, 1997, p. 10.

3. Léon de Saint Moulin, Comment réagir en chrétien face aux problèmes de société? Une session sur le discours socio-politique de l'Eglise catholique en RDC, Kinshasa, Cepas, 2002, p. 19.

4. Palabras finales de una de las últimas cartas de Mzee Munzihirwa. 
Esto es lo que queremos recordar en la primera parta de este artículo. En una segunda parte analizaremos cómo Mzee Munzihirwa veía la muerte y el martirio que presentía, y con que espíritu lo enfrentó.

\section{La familia y la educación, fundamentos de la paz y el desarrollo}

Para Mzee Munzihirwa presupuestos muy importantes para el desarrollo y la paz son la familia y la educación. Veámoslo.

\subsection{La familia como fundamento de una sociedad responsable}

Mzee Munzihirwa reflexionó frecuentemente sobre la familia. Su concepción está basada en una sencilla convicción: el futuro de nuestra sociedad depende de la calidad de nuestras familias. Desde esta perspectiva escribe: "cuando en un país las familias son estables, cuando los padres y las madres respetan la palabra dada, y cuando se dedican a la educación de sus hijos, el estado tiene una base sólida para gestionar el bien común de una nación y para hacer frente a los azares de la historia"5.

La familia es importante no sólo para la persona que es miembro de ella y su desarrollo personal. Su importancia se extiende a toda la sociedad. Un niño que nace y crece en una familia digna de ese nombre se convierte en un precioso don para toda la sociedad. Sin familias estables en las que reinan el amor y la solidaridad, en las que se enseñan los valores morales, espirituales y culturales, y en las que se transmiten esos mismos valores de generación en generación, ninguna sociedad puede desarrollarse. En lo esencial, en la familia se debe aprender y vivir el amor y la solidaridad. También en la familia aprenden los niños a ser responsables y solidarios para la gran obra de reconstruir la dignidad humana.

Pero hay que subrayar que la familia de la que habla Monseñor Munzihirwa es la que está fundada en el matrimonio.

El evangelio de Jesucristo recuerda la perspectiva primordial del matrimonio según el designio del creador: "el varón abandonará a su padre y a su madre para unirse a su mujer y para formar con ella una única persona, un solo principio de vida". Desde entonces, la cultura judía cristianizada y otras culturas marcadas por la influencia del evangelio darán una importancia esencial a la paternidad conyugal, una, intensa, firme, como base de la sociedad ${ }^{6}$.

Esta es la concepción de familia a partir del matrimonio que la Iglesia enseña y defiende desde siempre. En su exhortación apostólica Familiaris Consortio es-

5. Mzee Munzihirwa, "Le Zaïre face à l'ávenir des familles”, Zaïre-Afrique 206 (1986) 327.

6. Mzee Munzihirwa, "Jeunesse et développement au Zaïre en dialogue avec la famille et la nation en voie d'inculturation", p. 481. 
cribe el Papa Juan Pablo II que "según el designio de Dios, el matrimonio es el fundamento de esta comunidad más amplia que es la familia, pues la institución misma del matrimonio y el amor conyugal se ordenan a la procreación y a la educación de los hijos, en los que encuentran su plenificación" (cfr. GS 50)7.

Sin embargo, reducir el matrimonio a dos, esposo y esposa, corre el riesgo de no hacernos captar todo el alcance que Mzee Munzihirwa otorga a la unión de una mujer y un varón. En efecto,

tras los dos que hacen el contrato de matrimonio existe la sabiduría cultural cuyas expectativas son vividas como los valores que hay que respetar. Existe sobre todo un tercer personaje que confirma su contrato y lo transforma en sacramento de vida divina, el Cristo actuante en la dinámica del designio creador. Él debe permanecer como punto de referencia en el diálogo entre los esposos. Cuando deja de serlo, el diálogo se desvanece con facilidad. Allí donde Cristo ya no es amado, cada uno de los cónyuges descubre que aquél a quien más ama es a sí mismo. Su unión ha perdido el misterio que les engrandece... En tales circunstancias, en matrimonios plurales, queda truncada la educación, y la herencia cultural y económica ya no es transmitida a los descendientes como ocurre cuando cada uno de los cónyuges, padre y madre, cumplen su función ${ }^{8}$.

Mzee Munzihirwa, al reflexionar sobre la familia africana, abordó también la cuestión de la poligamia, insistiendo en el hecho que hace falta "renovar la familia siguiendo un camino distinto al de volver, sin reflexionarlo a fondo, a ciertas costumbres del pasado". Con respecto a la poligamia, Mzee Munzihirwa fue muy explícito. "Viendo las cosas más de cerca, se constata que el Africa bantú no era en su mayoría polígama: tener muchas mujeres era patrimonio de los ricos y los jefes. Pero no todo el mundo era rico ni era jefe. Se trataba, pues, de una minoría. El pueblo era de condición pobre; en su mayoría monógamo" ${ }^{10}$. Mzee Munzihirwa sitúa, pues, la familia en la concepción cristiana, la que nace del matrimonio y de su indisolubilidad. El papel del padre y de la madre, unidos por el vínculo del matrimonio, es, según esto, de importancia capital para la construcción de una sociedad estable. Fundada sobre el matrimonio, la familia se convierte, sin ninguna duda, en el santuario de la vida. En ella, más que en cualquier otro lugar, la vida, ese precioso don de Dios (Jn 10, 10), es acogida y protegida.

Según esto, la familia es esencialmente educadora. En este trabajo de educación se logra que el hombre y la mujer queden configurados según la plenitud de

7. Familiaris Consortio 14.

8. "Le Zaïre face à l'avenir..." 332-333.

9. Jeunesse... p. 485.

10. Ibíd., p. 485. 
la dignidad personal en todas sus dimensiones, en especial en la dimensión social. Para la familia educadora se trata de enseñar, mejor aún de transmitir - fiel al evangelio, a la enseñanza de la Iglesia y a las costumbres ancestrales positivas- los valores culturales, éticos, sociales y religiosos, que son esenciales para el desarrollo integral e integrado de la humanidad.

El papel tanto del varón como de la mujer son, pues, fundamentales. Mzee Munzihirwa, sin embargo, los distingue para dejar que emerja con mayor claridad su complementaridad.

\subsection{El papel del padre}

Un proverbio africano dice: "cuando mi hijo sea grande, habré hecho un hermano". Se trata de dejar en claro el papel que el padre debe jugar en el crecimiento de los hijos. A los ojos de Mzee Munzihirwa el papel del padre debe ser preponderante. Y lo explica de esta manera. "En toda familia humana, el padre es necesario no sólo para ser garante de los medios de subsistencia, sino sobre todo para configurar un conjunto de relaciones: relaciones entre la madre y los hijos, relación de los hijos entre sí, relaciones con los miembros de la familia, relaciones con todos los que no viven en el círculo familiar. El padre crea el equilibrio entre la cercanía y la distancia, entre la afirmación de las personas y las exigencias comunitarias, entre el medio familiar y la sociedad global. El padre hace posible que los hijos pasen del estadio primordial de naturaleza — que es apego inmediato-, a un estadio organizado en que la cultura crea distancias" 11 .

Pero esta función del padre sólo tiene valor cuando es ejercida por amor al hijo y a la sociedad en la que éste tendrá que jugar su propio papel. No se trata de que el padre actúe en lugar del hijo. Al padre sólo le toca liberar las potencialidades del hijo, pues él debe ser para el hijo, y el hijo no debe ser para él ${ }^{12}$.

Mzee Munzihirwa otorga al padre de familia, como hemos visto, una función eminente educadora. En efecto, "el padre, como educador, pone a la obra su potencial de amor con la continuidad de su presencia física y su sabiduría puesta al servicio del crecimiento" 13 . Pero el padre sólo puede desempeñar con éxito esta función en colaboración efectiva y afectiva con la madre.

\subsection{El papel de la madre}

Los escritos de Mzee Munzihirwa a propósito de la madre en particular y de la mujer en general pueden interpelar muy bien a nuestra sociedad en la que la mujer puede ser desconocida y subestimada. Y propone algunas precisiones: "no

11. Mzee Munzihirwa, “Former les citoyens de demain”, Zaïre-Afrique 192 (1985) 83.

12. Ibíd.

13. Ibíd., 84. 
es la madre, como se suele pensar, el agente principal de la educación; ella es más bien el canal, un camino que se abre en un mundo en el que prevalecen las relaciones de derecho, mundo en el que se ejerce en prioridad el papel del tío del hijo (recordemos las estructuras parentales donde el tío juega un papel fundamental en la familia)". Y explicita su pensamiento con proverbios africanos. Permítasenos citar, sin comentarios, algunos de ellos que dan luz sobre el papel de la mujer en la sociedad. "El mejor regalo que un padre puede hacer a su joven hijo, es amar a su madre". "Una idea sólida sólo habita en el corazón del hombre cuando, antes, ha atravesado el corazón de su madre"."Educar a un hombre es educar a un individuo, pero educar a una mujer es educar a todo un pueblo".

A los ojos de Mzee Munzihirwa, si la misión casi divina de la mujer, es la maternidad, es decir, casarse y tener hijos, "esta maternidad no es sólo biológica sino también espiritual. A través de ella, la mujer se revela como bisagra entre dos mundos. Es a la vez el ser más carnal y el ser más espiritual. La madre-muntú tiene un sentido de la vida tan natural y tan profundo que a propósito de ella bien podemos servirnos de la expresión de San Agustín: 'ella es carnal en el espíritu y espiritual en la carne""14.

En el pensamiento de Mzee Munzihirwa el papel que juega la mujer en el desarrollo queda claramente de relieve cuando escribe que "una cultura en la que el sentido de la madre está verdaderamente vivo, posee la base de la promoción de la mujer y el fundamento de un desarrollo lleno de promesas" ${ }^{15}$.

Monseñor Munzihirwa dedicó un poema a la mujer africana que, por sí sólo, resume lo mejor de su pensamiento sobre la mujer y sobre su papel en la sociedad. Permítasenos citarlo.

A ti te hablamos, Mujer muntú, que aspiras con razón a ser madre, esposa única y ciudadana a tiempo completo en la vida social, económica y política, Persona ilustre de nuestra civilización, Ministra del tráfico de la sangre y de la cultura de base - la lengua que hablamos, ¿no es la lengua materna? Fuerza, entre otras cosas, misteriosa y preciosa, que alimenta la vida naciente. Eje del crecimiento, de sucesión de generaciones, tienes razón para reclamar al padre la plena corresponsabilidad en la educación de los hijos que tú has engendrado no para ti misma, ni para el clan, ni para el estado, sino para ellos mismos, de modo que, cuando sean mayores, se pongan libre y voluntariamente al servicio el uno del otro. En cada una de las etapas tú eres madre, pero de forma diferente. Madre de futuras madres y de futuros padres de familia, madre de millones de hijos, madre de las plantas y de los hombres. Nada puede mejorar sin ti. Contigo todo queda ordenado, progresa y se desarrolla ${ }^{16}$.

14. Mzee Munzihirwa, Aux racines du développement, le rôle de la femme, p. 351.

15. Ibíd.

16. Ibid. 
Hablamos de la familia, con mayor precisión de la familia africana, en la que - y eso es lo que deseaba Mzee Munzihirwa — "los hijos deberán decirse que su padre es el menos imperfecto de los hombres, siendo su madre la más perfecta de las mujeres; familias en las que el hombre hace las leyes y la mujer hace las buenas costumbres; familias en las que la autoridad paterna, atemperada por el amor materno, genera la armonía psíquica de un hogar abierto en el que la intimidad da forma a una atmósfera educadora" ${ }^{17}$. Este tipo de familias son capaces de educar a los hijos en la paz y en el desarrollo.

\subsection{La educación, requisito para la paz y el desarrollo}

Lo acabamos de ver. La familia y la educación están relacionadas de tal modo en la concepción de Mzee Munzihirwa que es difícil, si no imposible, hablar de una sin hablar de la otra. Estas dos cosas, y las realidades que vehiculan, están asociadas de tal manera que el fracaso de una entraña inevitablemente el fracaso de la otra, y al final el deterioro de toda la nación. ¿No estamos, ahora, en trance de asistir a la desintegración de la familia y de la sociedad? Dicho con más precisión, la debacle actual de nuestra sociedad, a la que asistimos impotentes, ¿no es la consecuencia de la debacle del sistema educativo? Vamos a analizarlo en dos partes: la educación familiar y la educación escolar, profesional y universitaria.

Cuando hablamos de educación familiar se trata de "la educación familiar que está enraizada en el poder del amor de un padre, que se desarrolla en la regulación de las iniciativas personales, en el respeto a los otros, en el diálogo en el que se afrontan y armonizan los dinamismos más audaces y más universales" ${ }^{18}$.

En ese ambiente, el padre juega el papel del educador responsable. A este educador Mzee Munzihirwa lo describe como "aquel que hace que el niño pase de las condiciones primarias de familiaridad a las iniciativas personales que le permiten desprenderse de ciertos lazos familiares. La educación abre el camino al riesgo, pero lo canaliza según las fuerzas del niño... El padre es quien ayuda a pasar de los caprichos a la aceptación de realidades, al reconocimiento de los derechos y al respeto al otro" 19 .

El papel del padre no está fijado de una vez para siempre, sino que "se orienta, con naturalidad, hacia los horizontes más amplios de toda sociedad". En efecto, "la libertad que se promueve en la familia se expande en la nación bajo la autoridad de un jefe que coordina las diferencias y permite una cooperación creativa" ${ }^{20}$. Una sólida educación familiar es fundamento esencial para la educación escolar y universitaria.

17. "Le Zaïre face à l'avenir..." 332-333.

18. Mzee Munzihirwa, Former les citoyens de demain, 83.

19. Ibíd.

20. Ibíd., p. 84. 
La educación escolar y universitaria debe ser pensada como la que toma el relevo de la educación familiar. Se trata de formar "a los ciudadanos del mañana, preparando a los jóvenes para el respeto del derecho a la vida, del derecho al pensamiento autónomo, del derecho a la libre expresión de su fraternidad; se trata de preparar a los jóvenes para la escucha y el diálogo, al cambio que surge en el respeto a nuevos mensajes, a la creatividad del servicio de un bien común siempre más grande" $"$.

En una conferencia que tuvo en la Universidad de Bukavu el 19 de octubre de 1996, diez días antes de su asesinato, hablando al cuerpo de profesores y estudiantes, Mzee Munzihirwa definió la misión de la universidad. "Lo que constituye la grandeza de una universidad, así como la de una nación, es saber manejar las diferencias en lugar de destruirlas. Esto es lo que estimula el espíritu de inventiva y de creatividad. Bien sabemos, les decía, de qué modo la ignorancia es la madre de todos los vicios, y que, tristemente, los regímenes dictatoriales diseñan sus programas de acción para domesticar a pueblos enteros bajo un terror y una injusticia clamorosas"22.

\subsection{Educar y formar a los jóvenes para la paz y el desarrollo}

Nada hay en Mzee Munzihirwa tan lleno de pasión como su sentido del futuro de nuestra nación. Para él, se trataba del futuro de la paz y el desarrollo que deben ser construidos gracias a una juventud cuidadosamente preparada por la familia y la educación. En la Conferencia a la que hemos aludido, Mzee Munzihirwa recuerda a los intelectuales que "si los grandes intelectuales europeos no tuvieron éxito en la tarea de detener la guerra de 1939-1946, después de la guerra sí lograron fundar una sociedad basada esencialmente en la competitividad pacífica y constructiva en lugar de la competitividad destructora y bélica"23.

El resultado palpable de tal esfuerzo es la paz que ahora conoce la Unión Europea, paz que genera respeto a los derechos humanos, y defensa y protección de las libertades que desembocan en el respeto a la dignidad humana.

La paz y el desarrollo a los que aspiran nuestro país, y todas las naciones, pasan por el eje de la lucha contra la ignorancia, el trabajo arduo y bien hecho, y el diálogo y la colaboración entre los pueblos. "Hagamos, pues, de la ignorancia nuestro caballo de batalla; y de la cooperación con todos los pueblos nuestra táctica para que reine la paz y la prosperidad. El trabajo, cuando hay cooperación y una gestión trasparente, constituye el secreto de la prosperidad"24.

21. Ibíd., p. 87.

22. Joseph Mukabalera Cigwira, op. cit., p. 302.

23. Ibid., p. 392.

24. Ibíd., p. 393. 
Mzee Munzihirwa insistía en que todas las naciones tienen necesidad de la paz para desarrollarse. No se trata, por lo tanto, de la paz de los ejércitos de aquellos que están todo el día en pie de guerra, ni de la paz de los cementerios. Se trata de esta paz viva y vivificante que permite desarrollar en nuestras universidades las ciencias económicas, jurídicas, agronómicas y médicas ${ }^{25}$.

\section{El martirio}

"El desarrollo es una conquista"26, decía Mzee Munziwirwa. Implica sacrificio, la muerte incluso. Pero es una muerte que aceptamos porque es un paso a la vida, la que Jesucristo ha venido a darnos en abundancia

Mzee Munzihirwa pensó mucho sobre la vida y la muerte. Aun antes de pensar en su propio martirio vio la muerte desde su relación con la vida: morir para la vida. Vio la muerte como principio y fundamento de una vida

Para los actos que constituyen la vida morir es importante, pues es un acto que se prepara durante la existencia que precede. Y el silencio final es una palabra de una gran riqueza para quien sabe escuchar en lo interior. "La muerte es la luna", dice un proverbio. "Nadie ha visto su cara oculta. No es otra cosa que la otra cara de la vida: la que nosotros no vemos nunca" ${ }^{27}$.

Este pensamiento lleva a la siguiente pregunta: ¿en qué circunstancias Mzee Munzihirwa habló y escribió sobre la muerte? ¿Cuál era la motivación? Pues bien, Mzee Munzihirwa abordó el problema de la muerte precisamente al reflexionar sobre el desarrollo. Escribe:

Si la muerte dijera que la vida es una delgada lámina entre dos nadas, la felicidad debe estar totalmente relacionada con ese breve "pasaje", y las políticas de desarrollo quedarán encerradas en un horizonte terrestre. Si, por el contrario, la muerte nos habla de una vida expandida, más plena, duradera, sin límites, la felicidad debe ser concebida desde una perspectiva de infinito, y las organizaciones socio-políticas deberán tener en cuenta la sed de absoluto que está en el corazón del hombre ${ }^{28}$.

Mzee Munzihirwa aborda la cuestión de la muerte poniéndola en relación con la vida, que debe ser conquistada dando lo mejor de uno mismo. De lo que se trata no es de la muerte, sino de la vida. "En lugar de vivir para morir, morimos para vivir. Nuestra existencia pasa, pues, de la vida a la vida". Esta meditación sobre la muerte nos ayuda a hacernos la pregunta fundamental de otra manera, y a implicarnos nosotros mismos en la respuesta: ¿podremos contribuir a construir

25. Cfr. ibíd.

26. Mzee Munzihirwa, Pour un chrétien, quel développment?, p. 403.

27. Ibíd.

28. Ibíb. 
la paz en un país en guerra si no tomamos conciencia de que morir es el camino obligado? En lugar del "quien quiere la paz, prepare la guerra", ¿no será mejor decir, siguiendo a Mzee Munzihirwa, "quien quiere la paz y el desarrollo, prepárese a morir"? Sus escritos responden sin ninguna ambigüedad. "La esperanza que nos aporta el Cristo resucitado es una esperanza de liberación del hombre, personal, colectiva y total, pero necesita hombres que estén dispuestos a pagar el precio: 'quien quiera guardar su vida la perderá, y quien la entrega por sus hermanos la salvará’”29.

Desde aquí podemos analizar mejor cómo comprendió el martirio Mzee Munzihirwa y con qué espíritu lo aceptó para sí mismo. Lo desarrollaré en tres puntos. En el primero mostraré que la cruz fue siempre el centro de la espiritualidad de Mzee Munzihirwa. En el segundo, que la lucha por la paz y la justicia fue su preocupación de pastor. En el tercero, que el amor de la cruz y la lucha por la paz y la justicia es lo que le llevó al martirio.

La causa inmediata de su martirio fue su compromiso en favor de los más pequeños, en particular los refugiados, pero la razón última hay que buscarla en su adhesión a Jesús en su preferencia por los pobres. Por su compromiso, Mzee Munzihirwa llegó a ser, sin ninguna duda, una persona incómoda para todos aquellos que, para satisfacer sus intereses egoístas, querían aprovecharse de la presencia de los refugiados en Kivi.

\subsection{La cruz como símbolo de amor}

Cuando medito los escritos de este pastor con una gran sensibilidad para con los refugiados me impresiona su referencia continua y constante a la cruz. Con el paso de los años la cruz se convirtió en la realidad desde la que evaluaba su vida de discípulo y de apóstol. Así aparece, por ejemplo, el 17 de agosto de 1983, XXV aniversario de su ordenación sacerdotal, en una oración que tituló "recuerdo silencioso de mi sacerdocio":

"Si participas en los sufrimientos de Cristo, alégrate. Cuando se manifieste su gloria, tu gozo no tendrá límites" (1Pedr 4, 13). Ante mi ordenación, deseaba que estas palabras iluminasen mis caminos. Desde hace tiempo he suplicado a Cristo que me conceda la gracia de conservar este mensaje en mi corazón; que el recuerdo de su cruz permanezca en lo más profundo de mi ser para que le siga con decisión como un verdadero compañero y sin alejarme nunca de él.... Virgen María, madre de Jesús y madre mía, tú has seguido a tu hijo, has vivido en su escuela desde el nacimiento hasta la edad adulta, en el camino de la cruz. Estuviste al pie de la cruz para guardar sus últimas palabras. Sola en la tierra para esperar la resurrección, participando en sus dolores, crucificado con él tu corazón, participaste en la gloria de la resurrección.

29. Ibíd., p. 411. 
El 21 de abril de de 1996, durante el sínodo africano en Roma, Mzee Munihizrwa tuvo una audaz intervención, en la que él mismo tomaba conciencia - y hacía que otros la tomaran — de que la cruz es el símbolo más grande del amor

No diré muchas cosas, pues sigo la pista de aquella que no es muy locuaz... Para Jesús y su madre, en unión con él, la cruz ha sido la suprema expresión de amor: "no hay amor más grande que dar la vida por aquellos a los que se ama". Que en África sea María quien ejerza su influjo maternal para un nuevo nacimiento de gobiernos fraternales, pues la unión hace la fuerza ${ }^{30}$.

Dicho en pocas palabras, Mzee Munzihirwa supo encontrar expresiones vigorosas para decir lo esencial de su convicción cristiana: la cruz como expresión suprema del amor. Para él, la expresión del amor mayor que puede tener un discípulo de Cristo es aceptar sufrimientos y humillaciones por sus hermanos y hermanas. Así, la cruz de Cristo permanece siempre como la señal de su pertenencia total a Cristo. Como discípulo de Cristo Mzee Munzihirwa escogió la vía difícil del sufrimiento y humillaciones, la vía de la muerte para manifestar el amor que tenía por los débiles.

Quiero insistir en la centralidad de la cruz en la espiritualidad de Mzee Munzihirwa, pues en ella se fundamenta y cobra sentido su lucha en favor de la dignidad humana. La mejor manera de hacerlo será retomar unas estrofas de una oración que él tituló "Marcha apoyado en el Cristo", que escribió para acompañar la lucha y el reconocimiento de la dignidad humana en nuestro país.

En camino con Cristo hacia la cruz, después con María, su madre,

nosotros lo acompañamos en el camino de la cruz.

Y después, permanecer a la escucha junto a la cruz

para recibir las últimas palabras.

Verlo morir por la humanidad y por los pecados, acompañarlo hasta la entrada en el sepulcro.

Regresar a la ciudad con José de Arimatea, Juan, Nicodemo, también con las santas mujeres,

hasta el alba de pascua.

Entonces, acoger al Resucitado que comunica su paz:

"La paz esté con ustedes".

Esta paz no es estática, sino dinámica, en marcha.

El camino es largo y doloroso,

Y lo que hace daño a los pies del viajero,

30. In memoriam, p. 28. 
dice un proverbio,

no es la longitud del camino,

sino las pequeñas piedras en los zapatos

durante la marcha.

En nuestros corazones los egoísmos son las piedras que molestan nuestra marcha espiritual.

Que el viajero se quite las piedras y la andadura será ligera.

Pero tenemos un compañero

que conoce bien el camino:

Él es el Camino.

Cristo es el camino. Ese camino que lleva a la resurrección pasando por la pasión es el que deber recorrer todo discípulo digno de ese nombre. Pero como es sabido, Cristo, después de su resurrección, ha deseado paz a sus discípulos (Jn 20, 19). También les has pedido que cultiven esa paz en medio de ellos (Lc 10, 5). La paz y la justicia, eso es lo que Mzee Munzihirwa se dedicó a cultivar en el mundo en que vivía.

\subsection{Mzee Munzihirwa: artesano de la paz y de la justicia}

El 7 de abril de 1994, cuando los obispos estaban reunidos en Roma en el sínodo africano, se desencadenó el genocidio ruandés. La tragedia hizo que un gran número de refugiados fuese a la ciudad de Bukavu. La presencia de los refugiados en Bukavu, en condiciones difíciles, es lo que, en mi opinión, movió a Mzee Munzihirwa a protestar contra esa forma de empobrecimiento humano. Como ha escrito el P. Benjami Fahri, S.J., "durante dos años, en numerosas y valientes tomas de postura, propuso un camino de paz para la región de los Grandes Lagos, y llamó la atención del mundo sobre las desastrosas consecuencias de una presencia de refugiados en su diócesis, ya superpoblada, proclamando el derecho de todos a una solución justa y no violenta”.

Es impresionante la actividad de Mzee Munzihirwa exigiendo que se respetase la dignidad de los refugiados. Esta lucha por su dignidad y por la verdad que libera es lo que le llevó al sacrificio supremo. Esto es lo que les dijo en la homilía del 24 de julio de 1994 en una misa que celebró para los refugiados.

Nosotros, cristianos, no podemos olvidar que Jesús, apenas nacido, vivió como refugiado en Egipto y que la historia de sus antepasados está llena de deportaciones, sin olvidar que Israel se liberó de la esclavitud de Egipto. Vivamos, pues, juntos como verdaderos cristianos zairotas y rwandeses, estos acontecimientos que interpelan a nuestra caridad y a nuestro crecimiento evangélico: de la crisis, el hampa saldrá deshonrada, y los verdaderos cristianos saldrán renovados. Hay cosas que no se pueden ver como se debe sino es con ojos que han llorado. Que el Señor enjugue nuestras lágrimas con el don de la paz. 
Mzee Munzihirwa no se contenó con celebrar la eucaristía a los refugiados. Hizo uso de su valentía profética para denunciar y protestar contra el modo como eran tratados. He aquí la protesta que dirigió al Gobernador de la región de Kivu del Sur, al Delegado de HCR en Bukavu y al Delegado de Caritas Internacional, que hizo pública el 23 de agosto de 1996:

Exigimos a los organismos de ayuda a los refugiados que asuman su responsabilidad para hacer uso incluso de medios extraordinarios para combatir una catástrofe que amenaza, tanto a los refugiados rwandeses empobrecidos y sin defensa, como a la población zairota que ha perdido la paz y su entorno vital, y está amenazada de epidemias, cuyos gérmenes ya se propagan en medio de la inmundicia que se acumula por todas partes. ¿Dónde está el gobierno del Zaire? ¿Dónde está el gobernador de la Región? ¡No hacen nada y dejan a la población sin autoridad civil, política o militar! ¿Y qué hacen las potencias internacionales para que llegue una paz verdadera, sobre todo a Rwanda, después de esta atroz guerra civil? Llamamos a todo el mundo. Que todos obedezcan a la ley del amor, predicado sin cesar por Cristo, que es el verdadero camino para la paz verdadera y absoluta.

Estas palabras, claras, no fueron del agrado de los que tenían alguna parcela de poder y no actuaban en favor de los refugiados. La postura de Mzee Munzihirwa molestaba. Había que eliminarlo, pues era una luz molesta. Con conocimiento de causa y con la mirada en el Señor, Mzee Munzihirwa caminaba hacia el martirio. No renunció a la lucha. Hizo la elección de dar testimonio de la verdad.

\subsection{El martirio: una elección radical por Cristo y por los pobres}

Mzee Munzihirwa era consciente de la suerte que podía correr por su compromiso con los pobres. Sabía que los que se llaman grandes de este mundo no aman la verdad que molesta. Estaba preparado para todo, sobre todo para la muerte. He aquí el testimonio del Padre Simon Pierre M'nteba S. J., Provincial de la Provincia de Africa Central, sobre su encuentro con Mzee Munzihirwa, en lo que predicó en la Iglesia del Sagrado Corazón (Gombe-Kinshasa) después del asesinato:

Todavía recuerdo la última conversación que tuvimos en septiembre pasado, la antevíspera de su regreso a Bukavu. Me djjo: "No se asuste si escucha malas noticias, sólo rece para que el Señor y la Virgen María nos acompañen hasta el final del camino". A mis palabras, algo escépticas, que le reprochaban que viera las cosas tan negras, me respondió con aquella sonrisa característica que parecía decir a su interlocutor: "No captas el fondo de las cosas. Pasemos página. Más tarde comprenderás". Lo que me golpeó en aquel momento no era la nota dramática de su resolución, sino la honda serenidad con 
que desgranaba sus palabras. Como si fuesen parte de un rosario interior, que había rezado antes una y mil veces ${ }^{31}$.

La serenidad con que Mzee Muzihirwa avanza hacia su asesinato es una gracia que sólo el Señor le podía conceder. Es una gracia que le había pedido desde hacía mucho tiempo. Así se desprende de lo que dijo el 8 de septiembre de 1985 en su homilía en la misa de los primeros votos de unos novicios jesuitas. En ella les recuerda que un discípulo de Cristo siempre debe estar preparado para todo, y debe estar listo para sacrificar su vida por sus hermanos y hermanas:

Cuando se sigue a Cristo, nunca se sabe qué puede ocurrir. Es una aventura. Ustedes han leído, creo, en las noticias de la Compañía del mes pasado que hemos tenido una larga lista de mártires jesuitas de estos últimos tiempos. Jesuitas que han sido asesinados porque se mantuvieron fieles a la misión que Cristo les había confiado. Y también hoy hay jesuitas en la cárcel porque no pudieron dejar de proclamar la caridad de Cristo. Ser asesinado, estar en la cárcel, no es agradable, no es algo que nos atraiga a no ser que seamos hombres verdaderamente unidos a Cristo. Si seguimos a Cristo hasta el final, estamos seguros de que participaremos en su resurrección. Entonces, hermanos ¡ánimo!

Mzee Munzihirwa estaba haciendo alusión, con seguridad, a los seis jesuítas asesinados en El Salvador ${ }^{32}$. Como ellos, tampoco él murió de cáncer, de malaria o de alguna otra enfermedad. No murió en su casa. Murió en la calle, como un ladrón. No murió solo, sino con su motorista, un pobre hombre inocente. Se pudo haber escondido y evitar exponerse en una ciudad, amenazada por la guerra de 1996 que llevó a cambiar el régimen de Congo-Kinshasa. Pero prefirió dar ánimo a la población empobrecida, pues no podía contar para ello con las autoridades militares y civiles de la ciudad. Así fue. Ante la retirada de las autoridades civiles y militares, se quedó como centinela de la ciudad. Ese mismo día había tenido una intensa actividad en favor de la paz.

Pero presentía que todo podía ocurrir. Unas ráfagas resonaron en el camino, y salió del vehículo. Tenía una cruz en la mano. Sólo el día después, las personas que, en su huída, vieron su cuerpo inmóvil y sereno notaron que tenía un rosario cerca de la mano. Murió como había vivido: sencillo y despojado. ¿Hay que llorar? ¡No! Hay que dar gracias a Dios por el don de un pastor tan sencillo $y$ tan entregado. ¡Desde ahora es el que reza por la paz!

Mzee Munzihirwa. ¡Tú estás ahora con todos aquellos que han muerto por los pobres! Estás con ese puñado de hombres y mujeres que, como Monseñor

31. In Memoriam..., p. 15.

32. El 16 de noviembre de 1989 una treintena de militares invadieron el campus de la UCA, Universidad Centroamericana, y asesinaron cruelmente a los seis jesuitas, a su cocinera y a su hija. 
Romero $^{33}$, nos hacen comprender que morir por los pobres es un insigne martirio.

Los pueblos del Congo, en general, y los de Bukavu, en particular, siguen anhelando la paz, siguen sufriendo injusticias estructurales y siguen muriendo a causa de la pobreza y de la miseria total, que les son impuestas a través de estructuras sociales injustas. En ese tiempo de crisis, la valiente acción de Mzee Munzihirwa, a favor de los pobres y los marginados, interpela a todo aquel que se quiera apuntar al mensaje de las bienaventuranzas:

Felices los que tienen hambre y sed de justicia, porque serán saciados.

Felices los compasivos, porque obtendrán misericordia.

Felices los de corazón limpio, porque verán a Dios.

Felices los que trabajan por la paz, porque serán reconocidos como hijos de Dios.

Felices los que son perseguidos por causa de la justicia, porque de ellos es el reino de los cielos.

Felices ustedes cuando por causa mía los insulten, los persigan y les levanten toda clase de calumnias.

Alégrense y muéstrense contentos, porque será grande la recompensa que recibirán en el cielo. Pues bien saben que así persiguieron a los profetas que vivieron antes de ustedes.

Mzee Munzihirw. Descansa en paz.

33. El 24 de marzo de 1980, Oscar Arnulfo Romero, arzobispo de San Salvador, fue asesinado de un tiro en el pecho cuando celebraba la eucaristía en la capilla del Hospital de la Divina Providencia, hospital para enfermos de cáncer terminal. 